\title{
ESTUDIO DE PARÁMETROS REPRODUCTIVOS EN MARRANAS BAJO LA INFLUENCIA DEL NÚMERO DE PARTOS Y ÉPOCA DEL AÑO
}

\author{
STUDY OF REPRODUCTIVE PARAMETERS IN SOWS UNDER THE \\ INFLUENCE NUMBER OF BIRTHS AND TIME OF THE YEAR
}

\author{
${ }^{1}$ Daniel Gandarillas Espezua
}

\begin{abstract}
RESUMEN
De un total de 16 granjas, situadas en la periferia de la ciudad de Tacna, se han controlado 258 partos de 86 marranas de la raza Landrace X Yorshire. Mediante el análisis de varianza verificó el efecto de la estación y orden de parto sobre el tamaño de camada y peso al nacimiento y destete. En general, el tamaño de camada al nacer fue de 9,75 y al destete fue de 7,25 crías. El peso de las crias al nacer fue de 1390 gramos y al destete fue de 6819 gramos. Encontrando el menor peso en crias de madres con dos a más partos con 6473 gramos. El porcentaje de mortalidad fue de 17,5\% de un total de 258 partos, de una prolificidad de 10 lechones. Teniendo un porcentaje general de mortalidad de lechones durante el experimento de 17,5\%
\end{abstract}

Palabras Clave: Reproducción en marranas, marranas, parámetros en marranas.

\section{ABSTRACT}

From a total number of 16 farms in the outskirts Tacna city, 258 births of 86 sows of Landrace X Yorshire race have been controlled. Bymeans of the analysis of variance, the effect of season and order of birth over litter size, weight at birth and weaning were verified. Overall litter size at birth was 9.75 and weaning weight was 7.25. Piglets at birth weighted 1390 grams and at weaning 6819. Finding the lowest weight in offspring of mothers with two or more births with 6473 grams. The mortality rate was $17.5 \%$ of a total of 258 births, a prolificacy of 10 piglets. Having a general percentage of piglet mortality during the experiment of $17.5 \%$.

Key Words: Reproduction sows, sows, parameters in sows

\section{INTRODUCCIÓN}

En la producción porcina actual, una de las metas es obtener 10 a 12 lechones vivos por parto, (Buxadé, 1999). Sin embargo, este es un objetivo poco alcanzado, en especial cuando las condiciones de la granja son variables y las cerdas no llegan a responder de igual manera después del destete (Bhat, Mohan, \&Sukh, 2010). Los días de retorno al estro representan la forma de medir la respuesta reproductiva de la cerda destetada.

Estos factores además, constituyen parte fundamental de los días no productivos de la explotación, determinando así la fertilidad de la cerda. Disminuyendo los días no productivos e incrementando la prolificidad es una de las formas para aumentar el número de lechones por cerda/año (Trolliet, 2005). Los intervalos como el desteteestro y destete servicio fértil, son factores de riesgo para disminuir los días no productivos.

La productividad de la cerda es uno de los componentes en la producción porcina rentable, y la optimización de la productividad sigue siendo un reto importante para muchos productores. La marrana en la actualidad tiene el potencial de producir entre 60 y 70 lechones, en 6 ó 7 partos, a lo largo de su vida productiva. Aunque, son pocas las que logran. Sin embrago es común encontrar de 35 a 40 lechones (Carrero Gonzales, 1989). Esto representa una pérdida considerable tanto en eficiencia biológica como económica.

La pérdida excesiva de peso y la condición corporal durante la lactancia tiene efectos inmediatos y a largo plazo sobre el rendimiento (Germán Alarcón, Camacho Ronquillo, \& Gallegos Sánchez, 2005). Es decir, cuanto menor sea el consumo de alimento, mayor será la pérdida de peso corporal y condición corporal; también será menor el peso al destete de los lechones.

El tamaño de la camada al nacer y al destete y el peso promedio de las crías al destete están afectados significativamente por la paridad de las cerdas, obteniéndose bajos valores en cerdas primerizas (Gonzáles Hernández, de Armas Rodríguez, Paz Sieres, Guevara Viera, \& Tamayo Escobar, 2002).

Después del destete, la cerda necesita más tiempo para retornar al celo, peor aún si la alimentación es deficiente trayendo como consecuencia un celo débil, produce menos 
óvulos, resultando con camadas menos numerosas que pueden llegar a un sólo lechón (Hafez \& Hafez, 2002).

Durante la etapa de lactancia debemos lograr que las cerdas tengan una alta producción láctea para destetar lechones de buen peso, que pierdan poco estado corporal, que entren en celo rápidamente después del destete y que este sea un celo fértil y con una alta prolificidad para obtener muchos lechones en el siguiente parto (Buxadé, 1999).

En la presente investigación se ha determinado los factores que influyen en el tamaño de camada al nacer $\mathrm{y}$ al destete en lechones en granjas de porcinos de la ciudad de Tacna durante el periodo de abril a diciembre del 2013.

El objetivo de la presente investigación fue el estudio de los efectos de la época del año y del número de partos sobre el tamaño de camada y el peso de las crías al nacer $y$ al destete.

\section{MATERIALES Y MÉTODO}

Se han controlado 258 partos de 86 marranas de la raza Landrace X Yorshire de un total de 16 granjas colaboradoras, situadas en la periferia de la ciudad de Tacna, durante los meses de abril a diciembre del año 2013. Los datos fueron recopilados al finalizar el parto y al destete. La alimentación, instalaciones y el manejo seguian el esquema convencional que cumplían los propietarios. Los partos no recibieron asistencia. El destete se realizó con un promedio de 5,5 semanas de edad.

Todos los datos obtenidos fueron analizados a través de la estadística descriptiva.

Tabla $\mathrm{N}^{\circ} 01$. Distribución de partos registrados por estación y número de partos.

\begin{tabular}{lccc}
\hline & $\begin{array}{c}\text { Primer } \\
\text { parto }\end{array}$ & $\begin{array}{c}\text { Segundo a } \\
+ \text { partos }\end{array}$ & Total \\
\hline Otoño-invierno & 67 & 58 & 125 \\
Primavera-verano & 72 & 61 & 133 \\
Total & 139 & 119 & 258 \\
\hline
\end{tabular}

Para el análisis de datos de todos los objetivos se realizaron con un diseño irrestrictamente al azar a través de un modelo lineal aditivo.

\section{RESULTADOS}

\subsection{Tamaño de camada al nacer y al destete.}

El tamaño medio de la camada en general fue de 8,5. Según Youngquist, (1997) la camada ideal debería ser de 10,5 cría aproximadamente, por lo tanto existe una diferencia de 2 crías por parto. Esta diferencia afectará en la economía del productor. En hembras primerizas el tamaño de camada al nacimiento fue de 9,5 crías en época de otoñoinvierno o primavera-verano, y al destete fue de 7,5 crias respectivamente, mientras que en la camada de hembras de dos a más partos fue de 10 crías al nacer y de 8 crías al destete en épocas de otoño-invierno y de primavera-verano respectivamente. (Tabla $\mathrm{N}^{\circ} 02$ )

En general, el tamaño de camada al nacer fue de 9,75 y al destete fue de 7,25 En estación de otoño-invierno en marranas primerizas el promedio fue de 8 crias por camada y en marranas con más de dos a más partos fue de 7 crías. En las estaciones de primavera-verano fue de 9 crías; en marranas primerizas y en marranas con dos a más partos fue de 11 crías por camada, (Tabla $\left.\mathrm{N}^{\circ} 02\right)$.

Tabla $\mathrm{N}^{\circ} 02$. Relación de estación con tamaño de camada al nacer y al destete en primerizas y en marranas con dos a más partos

\begin{tabular}{lccccccc}
\hline & \multicolumn{2}{c}{$\begin{array}{c}\text { Otono- } \\
\text { invierno }\end{array}$} & \multicolumn{2}{c}{$\begin{array}{c}\text { Primavera- } \\
\text { verano }\end{array}$} & \multicolumn{3}{c}{ Promedio } \\
Estación & A & B & A & B & A & B & general \\
\hline Alnacer & 9 & 8 & 10 & 12 & 9,5 & 10 & $9,75 \mathrm{a}$ \\
Aldestete & 7 & 6 & 8 & 10 & 7,5 & 8 & $7,25 \mathrm{~b}$ \\
$\begin{array}{l}\text { Promedio } \\
\text { A }=\text { Primerizas }\end{array}$ & 8 & 7 & 9 & 11 & & & 8,5 \\
$\mathrm{~B}=$ Dosomás partos & & & & & & \\
\end{tabular}

\subsection{Peso de las crías al nacer y al destete}

En la Tabla $\mathrm{N}^{\circ} 03$, el promedio general el peso de las crías al nacer fue de 1390 gramos y al destete fue de 6819 gramos. Según fuente de Divasa-Farmavic (Informe técnico, 2013), el peso al nacimiento debería ser de 1500 gramos aproximadamente, por lo tanto, los lechones de este estudio están 110 gramos por debajo de lo que se consideraría normal. El peso de las crías al nacer y al destete en madres primerizas es de 1265 y 6473 gramos respectivamente; en madres de dos a más partos las crías pesaron 1516 y 7165 gramos al nacer y al destete respectivamente.

Tabla $\mathrm{N}^{\circ} 03$. Peso promedio de las crías al nacer $\mathrm{y}$ al destete según estación del año y orden de parto (en

\begin{tabular}{lccccccc}
\hline Estación & \multicolumn{2}{c}{ Otoño-invierno } & \multicolumn{2}{c}{ Primavera-verano } & \multicolumn{3}{c}{ Promedio } \\
& A & B & A & B & A & B & general \\
\hline N nacer & 1100 & 5800 & 1400 & 7100 & 1200 & 1510 & 1390 \\
Aldestetc & 1400 & 7100 & 1600 & 7200 & 6400 & 7160 & 6819 \\
\hline
\end{tabular}

\subsection{Mortalidad desde el nacimiento hasta el destete}

Como se observa en la Tabla $\mathrm{N}^{\circ} 04$, el porcentaje medio de mortalidad fue de $17,5 \%$ de un total de 258 partos, de una prolificidad de 9,75 lechones. Teniendo un porcentaje general de mortalidad de lechones durante el experimento de $17,5 \%$. Youngquist, (1997) reporta que el porcentaje de mortalidad ideal de una granja debería ser de $10 \%$. Habiendo una diferencia de $7,5 \%$.

Tabla N04: Efecto del orden de parto sobre el tamaño de camada (lechones nacidos vivos) y mortalidad de lechones durante la lactancia

\begin{tabular}{lccc}
\hline Orden de parto & $\mathbf{N}^{\circ}$ de partos & Prolificidad & $\%$ Mortalidad \\
\hline Primerizas & 139 & 9,5 & 17 \\
Dos a mas partos & 119 & 10 & 18 \\
Total & 258 & & \\
Promedio & & 9,75 & 17,5 \\
\hline
\end{tabular}

\section{DISCUSIÓN DE LOS RESULTADOS}

\subsection{Tamaño de camada al nacer y al destete}

El tamaño promedio general de la camada al nacer fue de 8,5 crías (prolificidad) (Ver Tabla $\mathrm{N}^{\circ} 02$ ) estos resultados son similares a los encontrados por Braun, Cervellini, \& Muñoz, (2012) que reportaron valores de 8,7 crías por camada. Son menores con los observados por Daza Andrada A. \& Gutierrez Barquin M. G., (1993) 
quienes reportaron 9,65 crías; sin embargo, otros trabajos han encontrado mayor tamaño de camada como 10,2 según Gonzales Hernandez et al., (2002) y Gómez, Ortega, \& Becerríl, (2009) reportaron 10,06 crías. De acuerdo con los valores encontrados en el presente trabajo la prolificidad es una muestra de la calidad de manejo que se da a las marranas en la granja, encontrando valores altos del número de camada en granjas tecnológicamente mejor equipadas con relación a las que no cuentan. Los resultados encontrados en el presente trabajo reflejarían el nivel de manejo en las granjas de nuestra región. Germán Alarcón et al., (2005) indica que el potencial productivo de una cerda ideal debe ser predecible; tener doce lechones por camada; sin embargo, Youngquist, (1997) recomienda tener como objetivo ideal de 10,5 crías por camada.

\subsection{Peso de las crías al nacer y al destete}

En el presente estudio no se encontraron diferencias significativas entre estaciones del año con referencia del peso al destete, excepto en primerizas en la estación de otoño-invierno con 5820 gramos se encontró una media de 6819 gramos al destete. Sin embargo, Campagna, Silva, Figueroa Massel, \& Velasco, (2008) reportaron que los mejores pesos al destete se lograron en otoño invierno y primavera con $8900 ; 9400$ y 8600 gramos respectivamente. También estos resultados son inferiores a los encontrados por Gonzáles Hernández et al., (2002) que es 7204 gramos. Esto puede estar influenciado por la temperatura ambiente y la humedad relativa; Bhat et al., (2010) refiere que el estrés térmico provocados por las temperaturas elevadas afecta negativamente la gestación y el desarrollo de los embriones. También reporta que a medida que se tiene un número mayor de crías por camada, disminuye el peso promedio de los lechones.

\subsection{Mortalidad desde el nacimiento hasta el destete}

Clowes et al., (2003) indican que la mortalidad de las crías al destete puede estar influenciado a la baja condición corporal de las marranas primerizas que entran al parto y durante la lactación necesitan mayor cantidad y calidad de alimentos, puesto que éstas todavía están en crecimiento, en lactación y haber sufrido estrés del parto.

La mortalidad de las crías pre destete puede también ser debidas a la emaciación y aplastamiento del lechón que pueden llegar a un $75 \%$ o más. Las pérdidas debido a la emaciación ocurren en los días 4 y 5 de vida, como resultado de la mala alimentación de la cría durante los días post parto. Los lechones muertos por aplastamiento por la madre generalmente tienen poco aumento de peso durante los primeros días de vida, (Gómez et al., 2009).

\section{CONCLUSIONES}

El peso de las crías al nacimiento no fueron las más ideales, influyendo negativamente la estación otoñoinvierno en cría de madres con dos a más partos.
La alta mortalidad del nacimiento al destete es preocupante puesto que es fundamental para el mantenimiento de población.

\section{RECOMENDACIONES}

Si bien, de acuerdo a esta experiencia los lechones más pesados al destete alcanzan el peso del mercado a menor edad que los destetados más livianos habría que corroborar esto en medios ambientales parecidos a los nuestros.

\section{REFERENCIAS BIBLIOGRÁFICAS}

Bhat, P. N., Mohan, N. H., \& Sukh, D. (2010). PIG PRODUCTION. India: Studiom Press.

Braun, R. O., Cervellini, J., E, \& Muñóz, M. V. (2012). Resultados sobre nacimientos ocurridos durante el período 2001 - 2010 en cerdas alojados al aire libre en la región semiárida pampeana. Posibles causas de muertes neonatales. Comunicación., 32.

Buxadé, C. (1999). Tomo VI Porcinocultura intensiva y extensiva (Vol. vi). ESPAÑA: Ediciones Mundi Prensa.

Campagna, D. A., Silva, P. S., Figueroa Massel, E., \& Velasco, L. (2008). Efecto de la Estación del Año sobre el peso al destete de lechones criados en un Sistema Porcicola al aire libre en Argentina. Memorias Del IX Congreso Nacional de Produccion Porcina.

Carrero Gonzales, H. (1989). Manual de Producion porcícola. Tulua.

Clowes, E. J., Aherne, F. X., Schaefer, A. L., Foxcroft, G. R., \& Baracos, V. E. (2003). Parturition body size and body protein loss during lactation influence performance.

Daza Andrada A., \& Gutierrez Barquin M. G. (1993). Efecto de la estación y orden de parto sobre el tamaño de camada y mortalidad de lechones durante la lactancia, 42 .

Germán Alarcón, C. G., Camacho Ronquillo, J. C., \& Gallegos Sánchez, J. (2005). Producción de Cerdos. México.

Gómez, B., Ortega, R., \& Becerríl, J. (2009). Factores que contribuyen en la variación del tamaño de la camada de lechones de líneas y cruces maternos., 16.

Gonzáles Hernández, C., de Armas Rodríguez, I., Paz Sieres, C., Guevara Viera, G., \& Tamayo Escobar, Y. (2002). Influencia del número de partos y la época del año sobre indicadores reproductivos en una unidad porcina, 14(2).

Hafez, E. S. E., \& Hafez, B. (2002). Reproduccion e Inseminacion Artificial en Animales (Septima.). Mac GrawHill.

Informe técnico. (2013). DIVASA -FARMAVIC SA. DIVASA FARMAVIC SA. Retrieved from http://www.produccionanimal.com/divasa-farmavic-s-adfv-lanza-al-mercado-emdocam-20-mgml/

Trolliet, J. C. (2005). Productividad númerica de la cerda, factores y componentes que la afectan. Producción Porcina. www.produccion-animal.com.ar.

Youngquist, R. (1997). Current Therapy in large Animal Theruigenology. Philadelphia: W. B. Saunders Company.

\section{Correspondencia:}

Daniel Gandarillas Espezua: gandarillasdaniel@hotmail.com
Fecha de Recepción: 08/05/2014

Fecha de Aceptación: 18/06/2014 